\title{
Mirror self-recognition in gorillas (Gorilla gorilla gorilla): a review and evaluation of mark test replications and variants
}

\author{
Lindsay E. Murray ${ }^{1}$ (D) James R. Anderson ${ }^{2}$. Gordon G. Gallup Jr ${ }^{3}$
}

Received: 3 August 2021 / Revised: 17 November 2021 / Accepted: 10 December 2021 / Published online: 7 January 2022

(c) The Author(s) 2022

\begin{abstract}
Mirror self-recognition (MSR), widely regarded as an indicator of self-awareness, has not been demonstrated consistently in gorillas. We aimed to examine this issue by setting out a method to evaluate gorilla self-recognition studies that is objective, quantifiable, and easy to replicate. Using Suarez and Gallup's (J Hum Evol 10:175-183, 1981) study as a reference point, we drew up a list of 15 methodological criteria and assigned scores to all published studies of gorilla MSR for both methodology and outcomes. Key features of studies finding both mark-directed and spontaneous self-directed responses included visually inaccessible marks, controls for tactile and olfactory cues, subjects who were at least 5 years old, and clearly distinguishing between responses in front of versus away from the mirror. Additional important criteria include videotaping the tests, having more than one subject, subjects with adequate social rearing, reporting post-marking observations with mirror absent, and giving mirror exposure in a social versus individual setting. Our prediction that MSR studies would obtain progressively higher scores as procedures and behavioural coding practices improved over time was supported for methods, but not for outcomes. These findings illustrate that methodological rigour does not guarantee stronger evidence of self-recognition in gorillas; methodological differences alone do not explain the inconsistent evidence for MSR in gorillas. By implication, it might be suggested that, in general, gorillas do not show compelling evidence of MSR. We advocate that future MSR studies incorporate the same criteria to optimize the quality of attempts to clarify the self-recognition abilities of gorillas as well as other species.
\end{abstract}

Keywords Evaluation $\cdot$ Gorilla $\cdot$ Method $\cdot$ Mirror self-recognition $\cdot$ MSR $\cdot$ Replication

\section{Introduction}

Mirror self-recognition (MSR), widely regarded as an indicator of self-awareness, has been studied in many species, notably primates, with mixed results. Although the strongest evidence for MSR in nonhumans has been found in great apes, one of the most perplexing species is the western lowland gorilla (Gorilla gorilla gorilla); positive evidence for MSR in gorillas is less consistently reported than for chimpanzees and orangutans. Our aim in this paper was to

Lindsay E. Murray

1.murray@chester.ac.uk

1 School of Psychology, University of Chester, Parkgate Road, Chester CH1 4BJ, UK

2 Department of Psychology, Kyoto University Graduate School of Letters, Kyoto, Japan

3 Department of Psychology, University at Albany, State University of New York, Albany, USA examine this issue by proposing a method to evaluate gorilla self-recognition studies that is objective, quantifiable, and easy to replicate. This method can be used as a form of quality control for MSR studies in other species too.

Although earlier, largely anecdotal descriptions of gorillas' reactions to their reflections existed (Benchley 1944; Hoyt 1941; Riopelle 1970; Yerkes 1927), Lethmate (1974) was the first to replicate the effects of the mark test, a systematic procedure introduced in Gallup's (1970) study of MSR in chimpanzees and three species of macaques. In the original mark test, the subject was anesthetized and then marked on a normally unseen body part (e.g. head, ear), observed in the absence of the mirror to record any spontaneous responses to the mark, and finally observed again in front of the mirror. Individuals who pass the mark test typically touch the mark while looking in the mirror or just afterwards; they often then look at and may smell their fingers. Suarez and Gallup (1981) introduced improvements to Gallup's (1970) original mirror exposure 
and mark test procedure by including a condition where anesthetized gorillas were not only marked on their faces but also their wrists, thus providing a control condition that can be used to demonstrate that the gorillas would in fact be interested in comparable marks on their faces if they were capable of mirror self-recognition. This is, therefore, the study we use as the reference point for evaluating all studies of gorilla self-recognition.

The literature on primate MSR since Suarez and Gallup (1981) is characterized by huge variability in target species, settings, methods, procedures, quality of evidence, and interpretations of the data. This variability has contributed to the mixed picture regarding MSR in gorillas. In addition, new theoretical perspectives have emerged; for example, relating MSR to neuroanatomical mechanisms (Hecht et al. 2017), which complement older approaches such as the "clambering hypothesis," which proposed the evolution of an awareness of personal agency for safe arboreal locomotion in large-bodied primates (Povinelli and Cant 1995). Gallup (1997) elaborated on this hypothesis, suggesting that whereas self-awareness was preserved in orangutans because of their arboreality, evolutionary developments were different for other ape species which became more terrestrial. For example, humans used self-awareness to compete among one another for scarce resources, gorillas may have lost the capacity due to genetic drift, while chimpanzees may even be in the process of losing the capacity. These hypotheses address both inter- and intra-species differences in MSR. Given that gorillas' sensorimotor and locomotor developmental trajectories differ from those of other great apes (Watts and Pusey 1993), it has been argued that gorillas' increasing terrestriality may have resulted in the evolving ancestral capacity for self-recognition being "turned off" (Povinelli 1993). An alternative suggestion is that the capacity for MSR evolved gradually, in incremental steps, rather than as an either/or emergence (de Waal 2019; Murray 2020; Murray et al. 2020). For example, gorillas' responses to their live video images have been categorized according to a continuum of different levels of self-recognition (Murray 2020$)$.

In the absence of any systematic analysis of studies of gorillas' responses to reflections, we examined the literature on gorilla MSR capacities in more detail. To this aim, we developed an evaluation procedure in which scores were assigned for key methodological features and for the outcomes of the studies, yielding an overall score for each study. We predicted, first, that MSR studies would score progressively higher as procedures, including behavioural coding methods, improve over time. Second, if improved procedures increase the likelihood of demonstrating MSR in gorillas, then the correlation between scores for procedures and outcomes should likewise be positive.

\section{Methods}

With reference to Suarez and Gallup (1981), we compiled a list of 15 methodological criteria and then scored all published studies of MSR in gorillas according to this list (see Table 1 for criteria and the rationale for each). Note that we included the early anecdotes of Yerkes (1927), Benchley (1944), Hoyt (1941), and Riopelle (1970) due to the scarcity of systematic studies. Each study received 1 point for each criterion that was met, 0 for each that was not met, or no score if details were not sufficiently clear.

Following initial piloting of these 15 methodological criteria, we added more weight to evidence of mirrormediated self-directed and mark-directed behaviour. For example, the Shillito et al. (1999) gorilla study received 10 points-more than Gallup's (1970) study of chimpanzees-despite finding no evidence of MSR in gorillas. Therefore, we awarded 5 points for spontaneous, mirrorguided, self-directed responses (i.e. using the reflection to investigate body parts that otherwise cannot be seen), and 10 points for unambiguous mark-directed responses while looking in the mirror.

For studies that included no mark test, only the first eight criteria were relevant, and with up to 5 points for evidence of mirror-guided self-directed responses, these studies could obtain a maximum of 13 points. For studies incorporating mark tests, all 15 criteria were relevant and, with up to 5 points for spontaneous self-directed responses and 10 points for positive mark-directed responses, the maximum possible score was 30 points. Applying this scoring system thus gave every published gorilla MSR study a methods score and an outcome score, in addition to the total score, which might be regarded as a "quality" score. For ease of comparisons between studies (those using the mark test and those not), scores were also converted to percentages of possible maximum score.

We used Spearman's rank order correlation to test our prediction that MSR methods would improve over time. Correlations were also used to test whether studies with higher methods scores yielded higher outcome scores, whether more positive findings were published more recently, and whether the overall percentage scores improved over time.

\section{Results}

Table 2 shows the 21 gorilla MSR studies included in the evaluation, with a brief description of their methods and the main outcomes. Fifteen studies employed a mark test and involved one to six subjects including male and female 
Table 1 Methodological criteria used to evaluate gorilla MSR studies

\begin{tabular}{|c|c|c|}
\hline Criterion & Description & Rationale \\
\hline 1 & Group (defined as $\geq 2$ ) vs. individual mirror exposure & $\begin{array}{l}\text { Provides more information about source of reflections (Gallup and } \\
\text { Anderson 2018) }\end{array}$ \\
\hline 2 & Minimum of 50 h' mirror exposure & Provides enough time for subject to learn to self-recognize \\
\hline 3 & Use of angled mirrors or televised live images instead of mirror & $\begin{array}{l}\text { Reduces eye contact and hence gaze aversion (Anderson and } \\
\text { Roeder 1989; Shillito et al. 1999) }\end{array}$ \\
\hline 4 & More than one subject tested & $\begin{array}{l}\text { Differentiates those studies where several individuals have mirror } \\
\text { access but only some are tested; accounts for individual variation }\end{array}$ \\
\hline 5 & Sessions videotaped and available for inspection & Provides lasting evidence for scrutiny \\
\hline 6 & Videos coded by 'blind' raters & Provides independence of interpretation of responses \\
\hline 7 & $\begin{array}{l}\text { Subject(s) adequately socially reared, displaying relative normal } \\
\text { behaviours }\end{array}$ & $\begin{array}{l}\text { Chimpanzees reared in isolation fail to self-recognize (Gallup et al } \\
\text { 1971) }\end{array}$ \\
\hline \multirow[t]{2}{*}{8} & Subject(s) mature enough (defined as $\geq 5$ years) for MSR & $\begin{array}{l}\text { Eliminates individuals not expected to achieve MSR due to imma- } \\
\text { turity }\end{array}$ \\
\hline & Additional criteria for mark test studies & \\
\hline 9 & Use of general anaesthetic or sham marking & Prevents knowledge about presence of the marks without a mirror \\
\hline 10 & Non-directly visible marks (e.g. on head) applied & Tests the use of mirror information about the self \\
\hline 11 & Control for tactile and olfactory cues & Prevents contamination from extraneous cues \\
\hline 12 & Directly visible control marks applied & Tests motivation to touch marks \\
\hline 13 & Post-marking observations, no mirror & $\begin{array}{l}\text { Tests spontaneous responses, without a mirror, as baseline control } \\
\text { for responses when mirror present }\end{array}$ \\
\hline 14 & Absence of humans during the test & $\begin{array}{l}\text { Prevents contamination of results due to facilitation, distraction, or } \\
\text { behavioural inhibition (Patterson and Cohn 1994) }\end{array}$ \\
\hline 15 & $\begin{array}{l}\text { Distinguishing between mark-directed responses in front of vs. } \\
\text { away from mirror }\end{array}$ & $\begin{array}{l}\text { Tests spontaneous responses to mark, without a mirror, as control } \\
\text { for responses to mark when mirror present }\end{array}$ \\
\hline
\end{tabular}

adults (note that Shillito et al.'s (1999) four experiments are treated as separate studies). Six studies described responses to mirrors (or equivalents) but conducted no mark test, and these involved one to four subjects, including males and females and some younger individuals. Typical responses to reflections included interest, social responses (sometimes decreasing over time) and selfdirected behaviours such as mirror-mediated examination of body parts. Mark tests gave rise either to touching or not touching the target mark.

Table 3 shows the scores for methods, outcomes and overall total for each study. For studies including a mark test, total percentage scores (where 100\% would be the highest scoring, therefore, highest quality, study) ranged from 20 to $80 \%$, with a mean of $47 \%$. Therefore, with Allen and Schwartz (2008) receiving the highest score of $80 \%$, and Shillito et al.'s (1999) Experiment 4 receiving the lowest score of $20 \%, 9$ of the 15 studies scored on or above average, and 6 scored below. For studies with no mark test, total percentage scores ranged from 8 to $85 \%$ (mean: $48.8 \%$ ), with Yerkes (1927) and Benchley (1944) scoring below average and the remaining four studies scoring above average. Methods scores for studies using the mark test ranged from 2 to 10 out of 15 , with a mean of 7.10. For studies with no mark test methods, scores ranged from 1 to 6 out of 8 , with a mean of 3 . In studies using the mark test, 8/15 (53\%) reported self-directed behaviour and 8/15 (53\%) reported mark-directed behaviour. All studies that reported markdirected responses also reported self-directed responses, with two exceptions: Swartz and Evans (1994) reported only self-directed responses, and Shumaker and Swartz (2002) reported mark-directed responses without self-directed behaviour. In studies not including a mark test, 4/6 (67\%) reported self-directed behaviour.

To highlight the criteria most associated with successful demonstrations of gorilla MSR, we calculated the number of studies using each of the 15 criteria. Table 4 shows that mark-directed responses were seen particularly in studies involving visually inaccessible marks, controls for tactile and olfactory cues, subjects who were at least five years old, and a clear distinction between mark-directed responses in front of versus away from the mirror. These criteria are also key features of studies finding self-directed responses. Additional criteria that appear important for the quality of studies include videotaping the tests, having more than one subject, testing subjects with adequate social rearing, reporting postmarking observations with mirror absent, and giving mirror exposure in a social versus individual setting.

The Spearman's correlation coefficient was positive and significant between methods score and year of study $\left(r_{\mathrm{s}}=0.55, N=21, p=0.005\right)$, demonstrating that, over time, studies became more methodologically rigorous. 


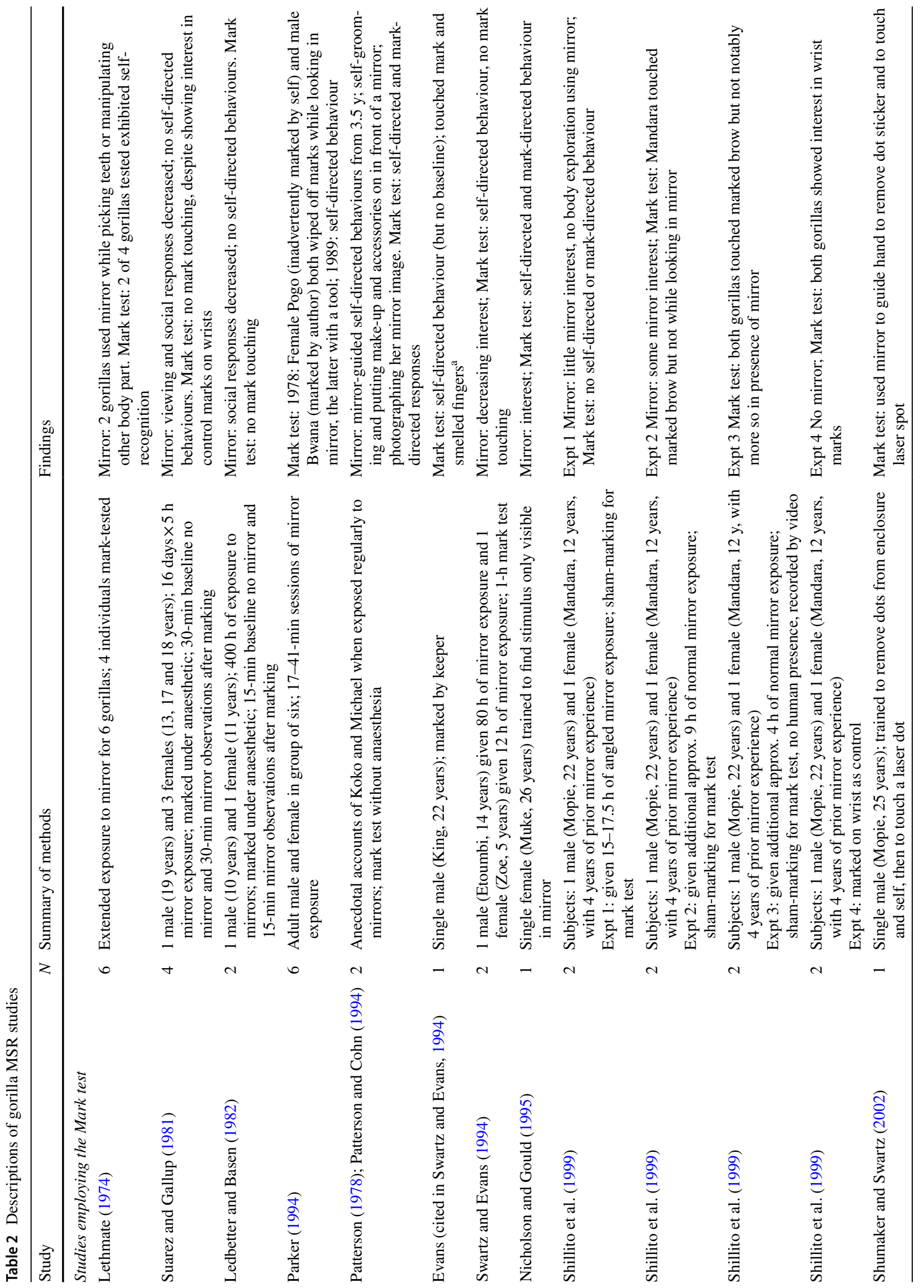




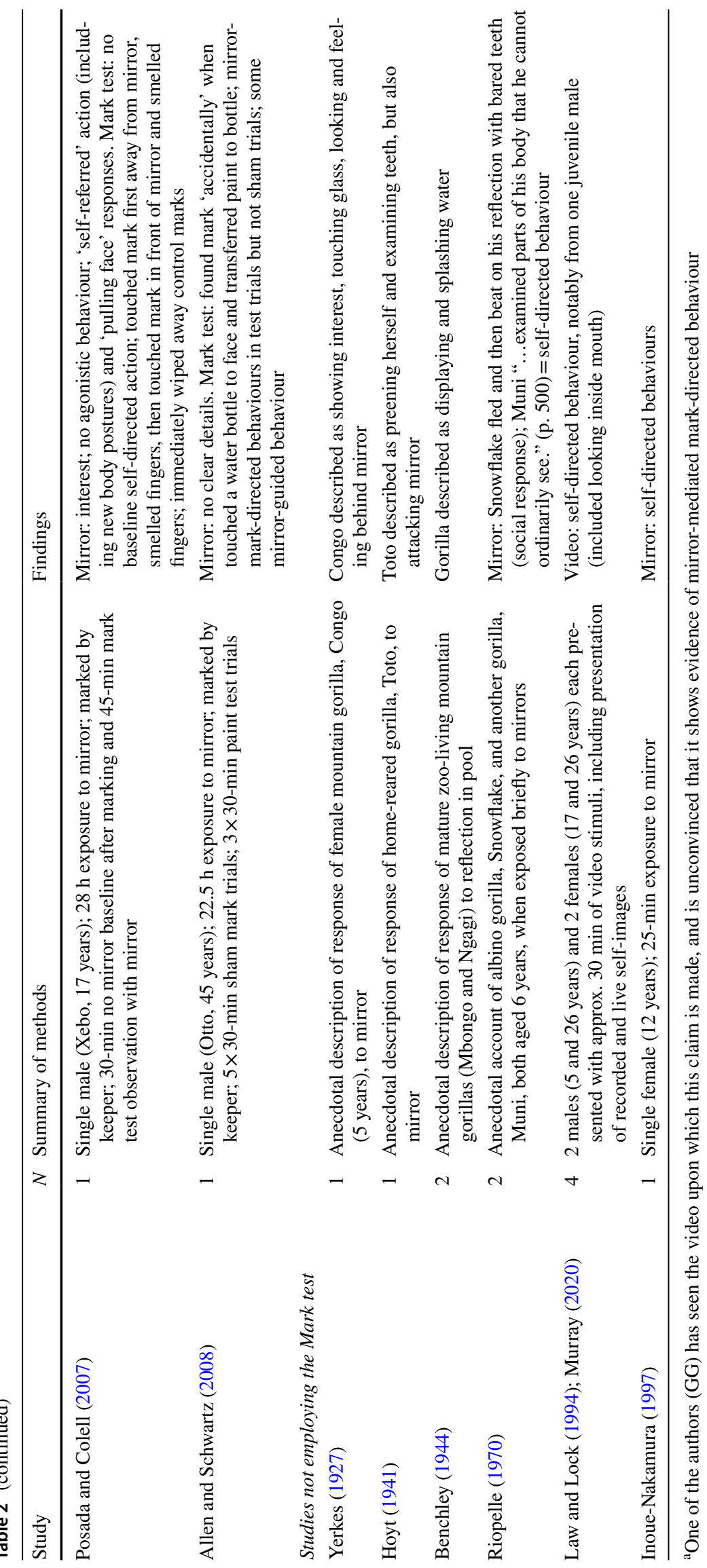




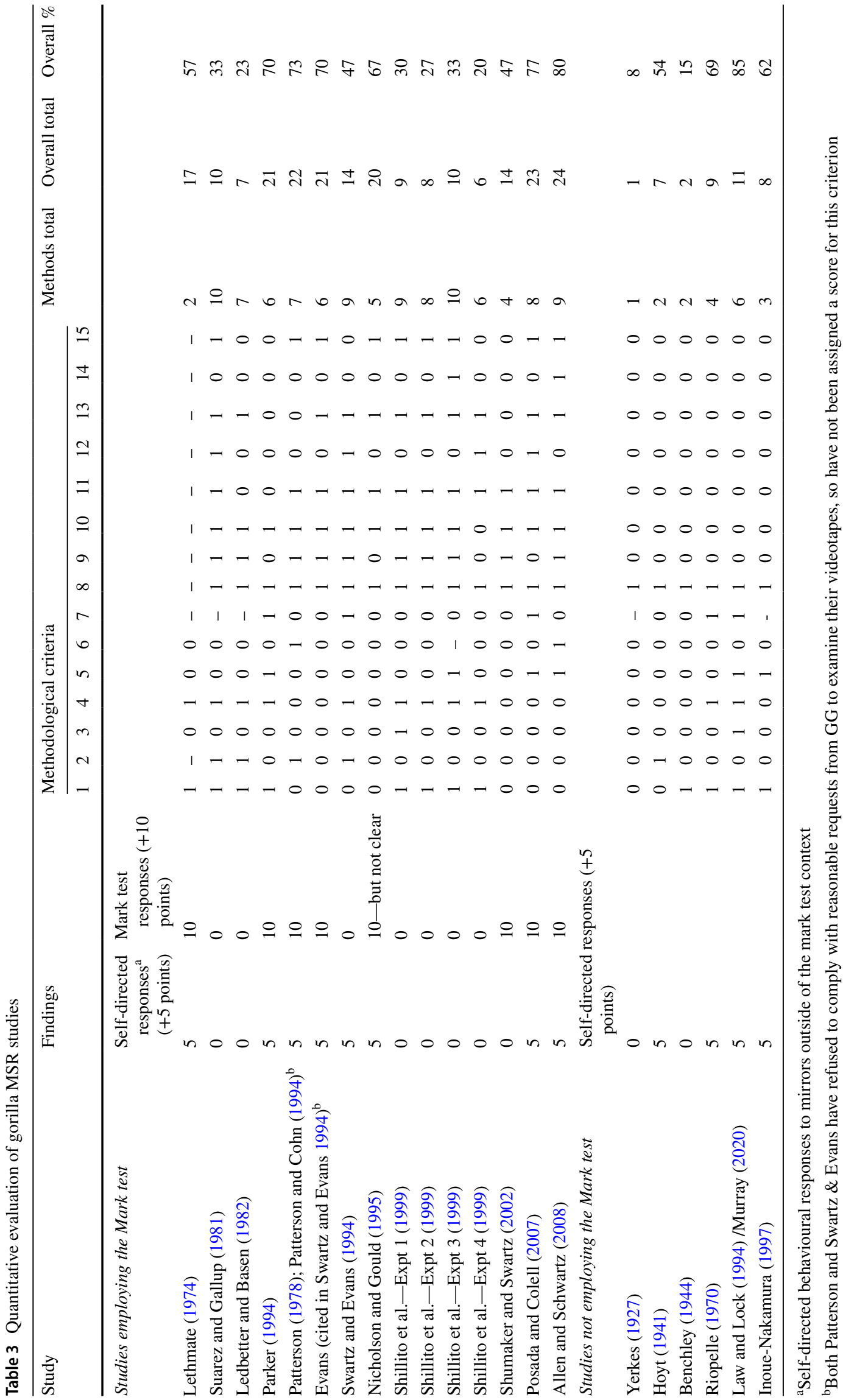


Table 4 Most frequently included criteria in studies reporting selfdirected and mark-directed responses to mirrors in gorillas (\%)

\begin{tabular}{lll}
\hline Criteria & $\begin{array}{l}\text { Mark-directed } \\
\text { responses }\end{array}$ & $\begin{array}{l}\text { Self-directed } \\
\text { responses }\end{array}$ \\
\hline Hidden Marks & 29.17 & 12.96 \\
Mature subjects & 25.00 & 20.37 \\
Cue control & 25.00 & 11.11 \\
Front v away from mirror & 20.83 & 9.26 \\
Group mirror exposure & & 9.26 \\
More than one subject & & 9.26 \\
Video recordings of responses & & 9.26 \\
Social grouping & & 9.26 \\
Post-mark observations & & 9.26 \\
\hline
\end{tabular}

Figure 1 shows that this is the case whether MSR studies included the mark test or not. However, higher scores on methodological rigour did not correlate with higher scores for outcome $\left(r_{\mathrm{s}}=-0.13, N=21, p=0.29\right)$, and the latter were not related to year of publication of the study $\left(r_{\mathrm{s}}=0.20, N=21, p=0.20\right)$. Finally, there was no significant correlation between overall total scores and year of study $\left(r_{\mathrm{s}}=0.27, N=21, p=0.12\right)$.

\section{Discussion}

We found a wide range of scores in our assessment of the quality of MSR studies in gorillas. Most of the studies with no mark test reported self-directed behaviour, while just over half of the mark test studies reported both self-directed and mark-directed behaviour. Over time, studies-with or without the mark test-have become methodologically more rigorous; however, this has not led to more positive outcomes. We found no link between when studies were conducted and either outcome or total scores (methodology and findings). Our prediction that studies would obtain progressively higher total scores as procedures and behavioural coding methods improved was not supported. However, when looking at the methodological criteria alone, the prediction was supported, as scores for methodological rigour did increase over time. While methodological rigour is clearly important, improvements in methods do not guarantee stronger evidence of self-recognition in gorillas. This lack of association could be taken as evidence that, at the species level, gorillas do not show compelling evidence of MSR. Alternatively, it may reflect wide intra-species variability. Like many studies on various aspects of cognition, most gorilla MSR studies have small sample sizes. Much remains unknown about how other factors, such as rearing, experience and setting, interact with basic individual differences in self-recognition propensity.

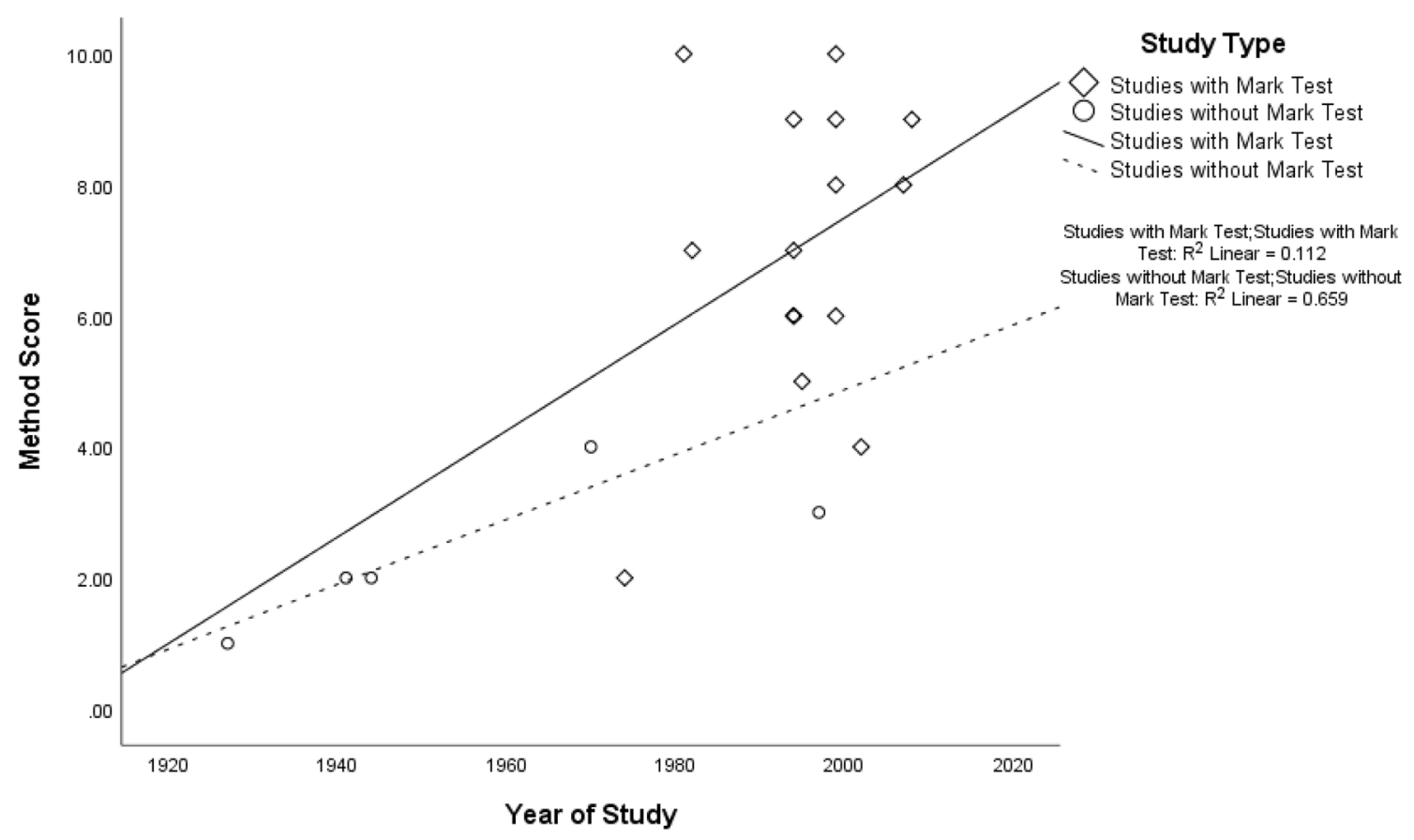

Fig. 1 Correlation between year of MSR study and methods score 
Awarding additional points for positive instances of both self-directed and mark-directed responses revealed that studies with no such responses received a low score, even if the method score was high, a trend reflected in the negative but non-significant correlation between methods score and outcome. Looking only at the methods totals (the 15 criteria), it is clear that the reference study (Suarez and Gallup 1981) scores the highest (10 out of 15 points), along with Shillito et al.'s (1999) Experiment 3. As methodologically stronger studies do not appear to yield more evidence of self-recognition in gorillas, procedural details seem unlikely to explain why positive evidence is so modest (de Veer and van den Bos 1999), although some authors have criticized use of a 'chimpanzee standard' to investigate MSR across species (Shumaker and Swartz 2002). Here, the argument is that the frequent failure of gorillas to pass the mark test may be due to as yet unidentified limitations of the mark test for revealing self-recognition in this species.

Contrary to the criticism of using a chimpanzee standard to investigate MSR in gorillas, it is important to examine those factors associated with positive responses in gorillas. Mark-directed responses occurred in studies involving visually inaccessible marks, tactile and olfactory controls, subjects of at least 5 years of age, and a clear distinction between responses in front of versus away from the mirror. These are clearly important factors which future studies on mirror self-recognition in gorillas should seek to replicate. Although gorillas often fail to respond to marks on their faces that can only be seen in a mirror, they do show an avid interest in comparable control marks on their wrists (Suarez and Gallup 1981). The results of studies that use dyes, stickers, or lasers, as in the trained monkey studies (Chang et al. 2017), have reduced validity as long as there are possible olfactory, tactile, or irritant cues from the marks. Shumaker and Swartz (2002) claimed to have found evidence of MSR in an individual gorilla who had previously failed (Shillito et al. 1999) using a training paradigm involving the use of stickers and lasers. According to these authors, their training procedures provided the necessary motivation for the gorilla to reveal his true ability. But it is important to bear in mind that trained positive outcomes are not the same as spontaneous ones (Gallup and Suarez 1986). Some other MSR studies with gorillas have included specific experimental manipulations designed to facilitate successful selfrecognition, including the use of angled mirrors, but without success (Shillito et al. 1999).

Additional important quality-related features of studies reporting mirror-guided self-directed responses include video-recorded tests, more than one subject, subjects with adequate social rearing, post-marking observations with mirror absent, and mirror exposure in a social versus individual setting. It is noteworthy that three gorillas reported to pass the mark test (Patterson and Cohn 1994; Swartz and Evans 1994) were raised in enculturated, enriched environments with extensive human contact, possibly resulting in a latent capacity for self-recognition being "switched back on" (Povinelli 1993). However, these results must be viewed as tenuous because of the lack of public availability of the relevant video evidence.

Gorilla MSR studies often involve removing subjects from their group for mirror exposure (e.g. Swartz and Evans 1994). This separation may negatively affect both those left behind in the group and the separated individual, particularly if they are immature. The emotional response to the separation, coupled with lack of experience in cognitive studies, may lead to attentional and emotional barriers to optimal performance in the test. Allen and Schwartz (2008) suggested that, as their single gorilla 'passed the test' without showing prior mirror-guided or contingent behaviours, these may not be pre-requisites. But contingency testing is open to alternative interpretations; for example, the subject may simply be trying to get the other individual in the mirror to reciprocate and respond normally instead of only mimicking the behaviour of the subject (Gallup and Anderson 2020). However, in Allen and Schwartz's (2008) report, the timings of multiple sham and test trials, and whether the mirror was present or not are often unclear, and so assigning scores was not always easy. To facilitate future evaluations, we recommend that due attention be paid to details when describing methods and observations. These details should include observing and reporting responses in front of versus away from the mirror, and post-marking observations with mirror absent.

It is also important to acknowledge that applicability of our evaluation criteria has changed over time. For example, fewer early studies included video recordings. But with the modern widespread availability of video, hopefully more researchers will be open to sharing footage in response to reasonable requests. Finally, studies should include not just ratings by "blind" observers, but also reports of inter-rater reliability.

In conclusion, we tried to scrutinize every published paper addressing the question of mirror self-recognition in gorillas, examining methodological details both alone and in combination with reported occurrences of self-directed and mark-directed responses. We hope that researchers might heed the criteria used here, particularly those highlighted in Table 4, to optimize the quality of future studies of the self-recognition abilities of gorillas as well as other species.

Author contributions LEM: conceptualization, methodology, formal analysis, resources, data curation, writing — original draft, writingreview and editing, and visualization. JRA: conceptualization, methodology, and writing-review and editing. GGG: conceptualization, methodology, and writing - review and editing. 
Funding None.

Availability of data and material Available.

Code availability Not applicable.

\section{Declarations}

\section{Conflict of interest None.}

Ethics approval The article used published sources which have each independently gone through ethical permission checks. No new research involving live animals took place.

\section{Consent to participate Not applicable.}

Consent for publication Not applicable.

Open Access This article is licensed under a Creative Commons Attribution 4.0 International License, which permits use, sharing, adaptation, distribution and reproduction in any medium or format, as long as you give appropriate credit to the original author(s) and the source, provide a link to the Creative Commons licence, and indicate if changes were made. The images or other third party material in this article are included in the article's Creative Commons licence, unless indicated otherwise in a credit line to the material. If material is not included in the article's Creative Commons licence and your intended use is not permitted by statutory regulation or exceeds the permitted use, you will need to obtain permission directly from the copyright holder. To view a copy of this licence, visit http://creativecommons.org/licenses/by/4.0/.

\section{References}

Allen M, Schwartz B (2008) Mirror self-recognition in a gorilla (Gorilla gorilla gorilla). Electron J Integr Biosci 5:19-24. http:// clt.astate.edu/electronicjournal/

Anderson JR, Roeder J-J (1989) Responses of capuchin monkeys (Cebus apella) to different conditions of mirror-imagestimulation. Primates 30(4):581-587. https://doi.org/10.1007/BF02380884

Benchley BJ (1944) My friends the apes. Faber \& Faber Ltd, London

Chang L, Zhang S, Poo M, Gong N (2017) Spontaneous expression of mirror self recognition in monkeys after learning precise visual-proprioceptive association for mirror images. PNAS. 114(12):3258-3263. https://doi.org/10.1073/pnas.1620764114

de Waal FBM (2019) Fish, mirrors, and a gradualist perspective on self-awareness. PLoS Biol 17:e3000112. https://doi.org/10.1371/ journal.pbio.3000112

de Veer MW, van den Bos R (1999) A critical review of methodology and interpretation of mirror self-recognition research in nonhuman primates. Anim Behav 58:459-468

Gallup GG Jr (1970) Chimpanzees: self-recognition. Science 167:8687. https://doi.org/10.1126/science.167.3914.86

Gallup GG Jr (1997) On the rise and fall of self-conception in primates. In: Snodgrass JG, Thompson RL (eds) The self across psychology: self-recognition, self-awareness, and the self-concept. New York Academy of Sciences, New York, pp 73-82

Gallup GG Jr, Anderson JR (2020) Self-recognition in animals: where do we stand 50 years later? Lessons from cleaner wrasse and other species. Psychol Conscious Theory Res Pract 7(1):46-58. https:// doi.org/10.1037/cns0000206

Gallup GG Jr, Suarez SD (1986) Self-awareness and the emergence of mind in humans and other primates. In: Suls J, Greenwald A (eds)
Psychological perspectives on the self, vol 3. Lawrence Erlbaum Associates, New Jersey, pp 3-26

Gallup GG Jr, McClure MK, Hill SD, Bundy RA (1971) Capacity for self-recognition in differentially reared chimpanzees. Psychol Rec 21:69-74

Gallup GG Jr, Anderson JR (2018) The "olfactory mirror" and other recent attempts to demonstrate self-recognition in nonprimatespecies. Behav Processes 14816-14819. https://doi.org/10.1016/j. beproc.2017.12.010

Hecht E, Mahovetz L, Preuss T, Hopkins W (2017) A neuroanatomical predictor of mirror self-recognition in chimpanzees. Soc Cogn Affect Neurosci 12:37-48. https://doi.org/10.1093/scan/nsw159

Hoyt AM (1941) Toto and I: a gorilla in the family. Lippincott, New York

Inoue-Nakamura N (1997) Mirror self-recognition in nonhuman primates: a phylogenetic approach. Jpn Psychol Res 39:266-275. https://doi.org/10.1111/1468-5884.00059

Law LE, Lock AJ (1994) Do gorillas recognize themselves on television? In: Parker ST, Mitchell RW, Boccia ML (eds) Self-awareness in animals and humans: developmental perspectives. Cambridge University Press, Cambridge, pp 308-312

Ledbetter D, Basen J (1982) Failure to demonstrate self-recognition in gorillas. Am J Primatol 2:307-310

Lethmate J (1974) Selbst-Kenntis bei Menschenaffen. Umschau $15: 486-487$

Murray LE (2020) Video-mediated behavior in gorillas (Gorilla gorilla gorilla): a stage in the development of self-recognition in a juvenile male? J Comp Psychol 134(3):293-302. https://doi.org/10. 1037/com0000216

Murray LE, Schaffner CM, Aureli F, Amici F (2020) There is no other monkey in the mirror for spider monkeys (Atelesgeoffroyi). J Comp Psychol 134(3):323-329. https://doi.org/10.1037/com00 00243

Nicholson I, Gould J (1995) Mirror-mediated object discrimination and self-directed behaviour in a female gorilla. Primates 36:515-521

Parker ST (1994) Incipient mirror self-recognition in zoo gorillas and chimpanzees. In: Parker ST, Mitchell RW, Boccia ML (eds) Selfawareness in animals and humans: Developmental perspectives. Cambridge University Press, pp 301-2307

Patterson F (1978) Conversations with a gorilla. Natl Geogr 154:438-465

Patterson F, Cohn RH (1994) Self-recognition and self-awareness in lowland gorillas. In: Parker ST, Mitchell RW, Boccia ML (eds) Self-awareness in animals and humans: Developmental perspectives. Cambridge University Press, pp 273-290

Posada S, Colell M (2007) Another gorilla (Gorilla gorilla gorilla) recognizes himself in a mirror. Am J Primatol 69:576-583. https:// doi.org/10.1002/ajp.20355

Povinelli D (1993) Reconstructing the evolution of mind. Am Psychol 48:493-509. https://doi.org/10.1037//0003-066x.48.5.493

Povinelli D, Cant J (1995) Arboreal clambering and the evolution of self-conception. Q Rev Biol 70(4):393-421

Riopelle A (1970) Growing up with snowflake. Natl Geogr 138:491-503

Shillito DJ, Gallup GG Jr, Beck BB (1999) Factors affecting mirror behavior in western lowland gorilla, Gorilla gorilla. Anim Behav 57:999-1004

Shumaker R, Swartz KB (2002) When traditional methodologies fail: cognitive studies of great apes. In: Bekoff M, Allen C, Burghardt GM (eds) The cognitive animal: empirical and theoretical perspectives on animal cognition. The MIT Press, London, pp 335-343

Suarez SD, Gallup GG Jr (1981) Self-recognition in chimpanzees and orangutans, but not gorillas. J Hum Evol 10:175-183

Swartz KB, Evans S (1994) Social and cognitive factors in chimpanzee and gorilla mirror behaviour and self-recognition. In: Parker ST, Mitchell RW, Boccia ML (eds) Self-awareness in animals 
and humans: developmental perspectives. Cambridge University Press, Cambridge, pp 189-206

Watts DP, Pusey AE (1993) Behavior of juvenile and adolescent great apes. In: Pereira ME, Fairbanks L (eds) Socioecology of juvenile primates. Oxford University Press, Oxford, pp 148-167

Yerkes RM (1927) The mind of a gorilla. Genet Psychol Monogr 2(1-2):1-193
Publisher's Note Springer Nature remains neutral with regard to jurisdictional claims in published maps and institutional affiliations. 